\title{
MUSIIKKI, ELOKUVAT JA ARVOSTUS
}

Elokuvamusiikkia ja elokuvamusiikin säveltäjiä arvostetaan nyt enemmän kuin koskaan aiemmin. Variety-lehti uutisoi 22.3.2019, että konserttisalien uusin vetonaula on elokuvasäveltäjiltä tilatut konserttiteokset, jotka vetävät salit täyteen kiinnostunutta yleisöä (Burlingame 2019). Valkokankaalta konserttisaleihin tehdyn siirtymän pioneeri oli John Williams, jonka eeppiseen sinfoniaorkestraatioon nojaavat elokuvasävellykset edustivat 1970-luvulla pastissinomaista paluuta klassisen Hollywoodin musiikinkäytön konventioihin mutta nykypäivänä edustavatkin neutraalia, jopa kansainvälisesti dominanttia, elokuvamusiikillista idiomia. Williamsilta on konsertteina kuultu elokuvien teemoja kierrättävän ohjelmiston ohella myös lukuisia alkuperäisteoksia. Ensin mainittua ohjelmistoa on tänä keväänä kuultu Helsingin musiikkitalollakin Vantaan viihdeorkesterin äitienpäiväkonsertissa 11.5.2019. Hieman toisenlaista repertoaaria mainostaa puolestaan kotimainen Gasthaus Orkesteri otsikolla "Music from the films of David Lynch". Lynch onkin sinänsä oiva konsertin aihe, onhan hän kaikista auteur-ohjaajista ehkä kaikkein "auteuristisin", sillä kirjoittaa itse myös lyriikat elokuviensa alkuperäislauluihin. Kaikkiaan tämä konserttibuumi on osoitus siitä, että elokuvien musiikiksi tarkoitetut alkuperäissävellykset ja myös elokuvamusiikkiin erikoistuneet säveltäät ovat jollain tapaa legitimoineet asemansa.

Toisenlaisesta arvostuksesta kertoo eri medioiden ja foorumien suosikkiajanviete - "kaikkien aikojen parhaiden soundtrackien" listat. Tänä keväänä ainakin Cosmopolitan (2019) ja The Independent (O'Connor 2019) ovat nettisivuillaan julkaisseet omat listansa, jotka olivat sisällöltään ja painopisteiltään sangen erilaiset. Toisen kärjessä komeili Quentin Tarantinon ohjaama Kill Bill vol. 1 (USA, 2003), toisen puolestaan Lady Gagan tähdittämä klassikkomusikaalin uudelleentulkinta A Star is Born (USA, 2018) - lukija saa itse arvata, kumpi oli kumman lehden ykkönen. Yhteistä molemmille listoille oli kuitenkin se, että ne koostuivat pääasiassa laulujen käyttöön vahvasti nojaavista elokuvista. Kuvaavaa on, että yksi harvoista molemmilta listoilta löytyvistä elokuvista ja samalla kummankin listan kaikkein vanhin elokuva oli Miehuuskoe (The Graduate, USA, 1967), joka onkin pop-kompilaatio-scorejen pioneeri. Nämä listat ja niiden jatkuvat laatiminen eri medioissa on osoitus, jos ei arvostuksesta, niin ainakin siitä, että ihmisiä kiinnostaa ja he pitävät elokuvien musiikin (ennen kaikkea laulujen) muistelemisesta, nimeämisestä ja arvottavasta listaamisesta. 
Miehuuskokeen lisäksi toinen yhteinen nimi kummallakin listalla on viime vuoden supersankarihitti Black Panther (USA, 2018), jonka musiikki voittikin parhaan "original scoren" Oscar-palkinnon. Palkinnon tosin sai elokuvan alkuperäisen score-musiikin säveltäjä, Ludwig Göransson, kun taas molemmat top-listat viittaavat vallan toiseen henkilöön: musiikintekijä ja tuottaja Kendrick Lamarin panokseen elokuvan sisältämien laulujen luomisessa ja kokoamisessa - Göranssonia ei näissä teksteissä edes mainita. Ruotsalainen Göransson haki inspiraatiota mustan vapaustaistelijasankarin tarinaa kuvaavan musiikin säveltämiseen muun muassa matkustamalla Afrikkaan ja nauhoittamalla paikallisia muusikoita Senegalissa (Flook 2017), mutta hän on hankkinut kannuksensa myös pitkällä yhteistyöllä USA:n rap-artistien kanssa. Hänen tuottamansa Childish Gambinon henkeäsalpaavan "This is America"kappaleen tyrmistyttävä musiikkivideo on ollut toinen voittoisa viime vuoden hitti: se sai MTV Video Music Awardsissa parhaan musiikkivideon palkinnon kategoriassa "Best Video with a Social Message" (2018).

Palkinnot ja niiden jakoperusteet kertovat usein mielenkiintoisesti siitä, mitä kokonaiset kulttuurit ja yhteisöt pitävät milläkin alalla arvossa. Parhaan musiikin Oscar-palkinnolla ei palkittu Kendrick Lamaria, eikä toistaiseksi ole palkittu myöskään Tarantinolle tai Stanley Kubrickille ominaisia eklektisiä lainamusiikkikompilaatioita hyödyntäviä elokuvia huolimatta siitä miten paljon yleisö, kollegat ja tutkijatkin niitä arvostavat. Jälkimmäinen epäkohta johtuu useimpien palkintokategorioiden vinoumasta, jossa vain alkuperäinen musiikki palkitaan - joko score (viitaten koko elokuvan kattavaan instrumentaalimusiikkiin) tai laulu (yksi kappale).

Oscar-palkintojen sääntöjen tuoreimmassa versiossa (Oscars 2019) todetaan, että ehdolle asetettava "original score" ei saa olla lainamusiikin tai laulujen "heikentämä" ("diluted", "diminished") eikä tekijänä voi olla enempää kuin yksi säveltäjä. Alkuperäisen laulun puolestaan tulee olla selkeästi elokuvan ohjaajan ja lauluntekijöiden yhteistyössä syntynyt, sen lyriikoiden tulee olla selkeästi kuultavissa, ja lopputeksteihin sijoitetuista kappaleista huomioidaan vain ensimmäinen. Sääntökuvaukset antavat selvän viestin - tai jopa kaavan - siitä, millaista yhdysvaltalaisten elokuvien musiikin katsotaan olevan tai millaista sen tulisi olla, vastasi se sitten todellisia käytänteitä tai ei. Mielenkiintoisena lisänä ensi vuoden palkintoihin tulee "best original musical", mikä ensimmäistä kertaa Oscar-palkinnon historiassa ottaa huomioon mahdollisuuden, että elokuvassa voi olla useampikin kuin yksi laulu - todennäköisesti A Star is Born -elokuvan menestyksen siivittämänä-mutta alkuperäisyydestä ei silti tingitä. Lisäksi laulujen (vähintään viiden) on oltava olennaisesti tarinaa eteenpäin vievä ("must further the storyline") elementti. Yksi harvoista liberaalimmin elokuvien erityyppisiä musiikkiratkaisuja palkinneista on AFN (Adult Film Network) Awards eli USA:n "porno-oscarit", jossa vuoteen 2009 asti alkuperäissävellykset kilpailivat rinta rinnan lainamusiikin - vaikkapa Van Halenin tai Bachin - kanssa, kunnes alkuperäissävellykset saivat alan säveltäjien vaatimuksesta oman, erillisen kategoriansa (ks. Harper 2014).

Tätä taustaa vasten näyttäytyy sangen yllättävänä viime vuonna Cannesissa jaettu Cannes Soundtrack -palkinto, joka annettiin venäläisen Kesä-elokuvan (Leto, 2018) "musiikillisille tuottajille" Roman Bilykille ja German Osipoville, joiden kontribuutio elokuvan musiikkiin oli olemassa olevien venäläisten rock-klassikoiden uudelleen sovitus elokuvaan. Se, että palkinto annettiin miehille, jotka eivät käytännössä olleet itse tehneet musiikkia elokuvaan, on merkittävä ennakkotapaus, joka meni silti läpi täysin ilman minkäänlaista kohua tai keskustelua. Tämä viittaisi siihen, että kyseessä oli enemmän po- 
liittinen kannanotto Putinin silmätikuksi joutuneen ohjaaja Kirill Serebrennikovin puolesta, ja taidepoliittinen kannanotto tuli tehtyä vain sivutuotteena ja puolivahingossa. Jää nähtäväksi, onko tällä eleellä mitään vaikutusta alan palkinnonjakokäytäntöihin - ainakin tämän vuoden Cannes Soundtrack -palkinto meni jälleen perinteisemmälle instrumentaaliteokselle.

Omaa tarinaansa musiikin ja tietyntyyppisten musiikillisten esitysten arvostuksesta kertoo myös tutkimuskohteeksi valikoituminen. Tämän Lähikuvan artikkelit kertovat jokainen riviensä välissä siitä, mitä tällä hetkellä Suomessa pidetään relevanttina tutkimuskohteena musiikin ja liikkuvan kuvan suhteessa. Rock- tai countrymusiikki, televisiosarjat ja musiikkivideot eivät vielä jokunen vuosikymmen sitten olisi välttämättä olleet itsestään selvästi tällaisen tutkimuksen keskiössä - imitaatioartisteista, naissäveltäjistä ja Timo Koivusalosta puhumattakaan.

Ira Österbergin artikkeli käsittelee jo mainitun venäläisen Kesä-elokuvan musiikinkäyttöä. Elokuvan vastaanotossa puhe on pitkälti keskittynyt siihen, miten elokuva (oletettavasti) kritisoi venäläistä nyky-yhteiskuntaa, siitäkin huolimatta, että kyseessä on musiikkielokuva. Yhteiskuntakritiikkiä elokuvasta saa hakemalla hakea, ja kyllä sitä sieltä mahdollisesti löytääkin, mutta pääosin se on kuitenkin täynnä nostalgiaa 1980-lukua ja erityisesti sen musiikkimaisemaa kohtaan. Österbergin formalistiseen rakenneanalyysiin ja elokuvamusiikin narratologiaan pohjaava tutkimus tuo esille sen, miten Kesän kompilaatio-score sisältää loppujen lopuksi hyvin monenlaista musiikkia - alkuperäistä, lainattua ja uudelleen tulkittua, elävää musiikkia ja tallenteita - ja nämä eri musiikkikategoriat suhteutuvat eri tavoin kerronnan tasoihin, joko realistisen dokumentin, musikaalifantasian tai postmodernin ekstrafiktion keinoin. Rock-laulujen kompilaatio-scorea hyödyntävä neuvostorokkareiden elämäkertaelokuva ei sitoudu minkään yksittäisen elokuvagenren musiikinkäytön konventioihin vaan muodostaa oman rakenteellisen lainalaisuutensa musiikin ja kerronnan tasojen suhteessa.

Kari Kallioniemen artikkeli paneutuu myös muusikoiden elämäkertaelokuviin, mutta luo niille kontekstia musiikintekijöiden ja taiteilijapersoonien esittämisen traditiosta käsin aina 1800-luvun säveltäjäelämäkerroista lähtien. Elämäkertojen esittäminen mediasta riippumatta näyttäytyy sarjana tiettyjä konventionaalisia esittämisen hetkiä, tai topoksia, jotka ovat säilyneet yllättävän muuttumattomina nykypäiviin saakka ja heränneet henkiin vaikkapa Timo Koivusalon muusikkoelämäkerroissa Kulkuri ja joutsen (Suomi, 1999), Sibelius (Suomi, 2003) tai Olavi Virta (Suomi, 2018). Kallioniemi osoittaa, kuinka itse musiikin lisäksi myös musiikintekijän elämänkaari ja persoona on tuotteistettu jo varhain - ja mielenkiintoista on, että sille on ollut myös alusta lähtien yleisön keskuudessa kysyntää.

Kaapo Huttunen problematisoi tanskalaisen nordic noir -sarjan Rikos (Forbrydelsen, 2007-2012) avaustuotantokauden musiikki- ja äänimaailman Lähi-itään ja islamilaiseen kulttuurin viittaavia tyylipiirteitä. Hän herättää kysymyksen, mitä ne tekevät sarjassa, jossa maahanmuuttajat, rasismi ja muut vastaavat temaattiset elementit eivät ole juonen keskiössä. Erityisen kiintoisan tapauksesta tekee se, että sarjan musiikkiin haettiin "pakistanilaista fiilistä", mutta lopputulos kuulostaakin arabialaiselta ja persialaiselta, jolloin päästään orientalistisen ajattelun äärelle. Tarkasteluun pääsee myös se, millainen vaikutus sarjan teko- ja julkaisuhetkellä Tanskassa vallinneella poliittisella ilmapiirillä on sarjan audiovisuaaliseen lähilukuun.

Katsaukset ja näkökulmat laajentavat tutkivaa katsetta (ja korvaa) fiktioelokuvasta ja -sarjoista myös muihin audiovisuaalisen esittävän taiteen 
muotoihin. Taneli Hiltunen nostaa valokeilaan historiallisten elokuvien ja tv-sarjojen brittinaissäveltäjät ja keskittyy erityisesti tunteiden ja ajankuvan ilmentämiseen. Vaikka naissäveltäjien noususta laajempaan tietoisuuteen on viime vuosina tullut aidosti globaali ilmiö - esimerkkeinä feministisen supersankarielokuvan Captain Marvel (2019) turkkilainen Pinar Toprak ja HBO-minisarjan Chernobyl (2019) islantilainen Hildur Guðnadóttir - juuri brittikonkarit, näkyvimmin Rachel Portman ja Anne Dudley, ovat erityisesti klassikkoromaaneihin perustuvien periodidraamojen saralla viitoittaneet tietä nuoremmille kollegoilleen. Myös uusi sukupolvi tiedostaa traditioiden merkityksen, mutta ei epäröi tarttua raskaisiinkaan aiheisiin ennakkoluulottomalla otteella, jolloin esimerkiksi Jackie Kennedyn lohdutonta ja sekasortoista mielentilaa kuvastavat Mica Levin loihtimat levottomat glissandot. Huomionarvoista on, että useat brittinaiset ovat klassisen koulutuksen sijaan ponnistaneet score-taitureiksi popmusiikin puolelta, mikä jo itsessään monipuolistaa äänimaisemia.

Roos Hekkensin aiheena ovat dokumentaaristen elementtien ja monikäyttöisen musiikkivideoformaatin yhdistämisen tuomat mahdollisuudet. Hekkens pohtii, millaisia eri funktioita dokumentaarisissa musiikkivideoissa käytetään "todellisuuden" representoimiseen. Pääesimerkkinä hän käyttää videota "Wyclef Jean", jonka ohjaaja Ryan Staake ja artisti Young Thug eivät koskaan tavanneet. Näin ollen siitä tuli erikoislaatuinen ja "pieleen menemisestään" huolimatta - ja juuri sen takia - itsessään ajatuksia herättävä.

Sirpa Reinikainen tutustuttaa tribuuttiesitysten maailmaan, joka on vähiten tutkittuja populaarikulttuurin ilmiöitä. Hänen pohdintansa lähtökohtana on artistin ja yleisön välinen vuorovaikutussuhde ja tribuuttibändien rooli suhteessa alkuperäiseen artistiin ja faneihin. Reinikaisen mukaan tribuuttiartistin ja yleisön välille rakentuu monitasoinen elämys, joka perustuu alkuperäistä artistia kohtaan tunnettuun kunnioitukseen sekä bändien ja yleisön halukkuuteen kuvitella olevansa "aidossa" esityksessä - hämärtää raja toden ja kuvitellun välillä. Yhteisellä sopimuksella tilanteesta tulee tavallaan todellinen, joskin yleisöä voidaan vieroittaa hetkellisestä illuusiosta muun muassa huumorin avulla, sillä kyse on imitaatioviihteestä, vaikka faneille sillä on paljon suurempi ja syvempi merkitys.

Olli Lehtonen tarkastelee, miten Sam Peckinpahin elokuvassa Nuori Bonner (Junior Bonner, 1972) musiikki ilmentää Etelävaltioiden cowboy-kulttuuria. Topokset ja stereotypiat ovat tärkeässä roolissa, ja Peckinpah sekä kunnioittaa perinteitä että modernisoi niitä ja myös kapinoi niitä vastaan jäljittelemättömään tyylinsä. Lehtonen limittää musiikkianalyysin visuaalisiin oivalluksiin, kuten kekseliäästi toteutettuun jaetun ruudun epäkronologiseen käyttämiseen elokuvan rodeoprologissa. Countrytyylinen alkuperäismusiikki sekä toisaalta genren laulaja-lauluntekijöiden esittämät kappaleet ja kuva luovat yhdessä merkityksiä, joiden juuret ovat syvällä alueellisessa kulttuuri-identiteetissä, populaarikulttuurin välittämissä käsityksissä siitä ja ylipäätään elokuvakerronnan tavoissa. Countrymusiikki onkin kaikissa käyttötarkoituksissaan Nuorelle Bonnerille kuin buutsit cowboylle - erottamaton osa kokonaisvaikutelmaa.

Arkiston kaksi aarretta nostavat esiin Lähikuvan lähes neljännesvuosisata sitten ilmestyneen musiikki-teemanumeron (2/1996) tekstit, joilla on edelleen paljon tietoarvoa myös nykylukijalle. Jukka Sarjala luotaa mykkäelokuvakulttuuria säestysmusiikin välittämien ja tuottamien affektien näkökulmasta tehden samalla teoreettista yhteenvetoa, josta hyötyy myös modernimman audiovisuaalisen kulttuurin tutkija. Suomalaisen elokuvamusiikintutkimuksen pioneerin, Anu Juvan, artikkeli puolestaan käsittelee musiikkia käytänteiden 
ja tekemisen näkökulmasta. Tekijähaastatteluiden ja arkistovalokuvien avulla Juva luo katsauksen ja samalla tallentaa arvokasta tietoa kotimaisessa elokuvamusiikissa 1950-ja 1960-luvulla tapahtuneista muutoksista niin tyylillisessä kuin teknologisessakin kehityksessä.

Voidaan sanoa, että yksi tutkijan keskeisistä missioista on löytää tutkimisen arvoista sieltäkin, missä muut eivät sitä näe. Aihevalintojen monipuolisuus ja eri oppiaineista kumpuavien lähestymistapojen ja metodologioiden demokratia sekä ei-arvottava ote itse tutkimuskohteeseen ovat hyvään tieteentekemiseen kuuluvia arvoja, joita kannattaa vaalia. Tämän Lähikuvan Musiikki-numeron monimuotoisuus osoittaa ainakin sen, että musiikin tutkimista audiovisuaalisen median ja populaarikulttuurin eri ilmiöiden osana ei tarvitse enää erikseen perustella - se on legitiimi ja arvokas aihe sinänsä.

Kesäkuussa 2019

Ira Österberg ja Taneli Hiltunen

\section{Lähteet}

Burlingame, Jon (2019) New Trend in Concert Halls: Original Music by Movie Composers No Film Required. Variety, 22.3.2019, <https://variety.com/2019/music/news/film-composerswrite-music-for-concert-halls-danny-elfman-james-newton-howard-1203170705/> (Linkki tarkistettu 25.6.2019.)

Cosmopolitan (2019) The Best Movie Soundtracks of All Time. Cosmopolitan, 20.2.2019, <https:// www.cosmopolitan.com/entertainment/music/g26427733/best-movie-soundtracks/> (Linkki tarkistettu 25.6.2019.)

Flook, Ray (2017) Musical Anatomy of a Superhero: The Best SDCC Panel That I Didn't Intend To See. Bleeding Cool, 21.7.2017, <https://www.bleedingcool.com/2017/07/21/surprise-supercoolsuperhero-music-panel/> (Linkki tarkistettu 26.6.2019.)

Harper, Davis (2014) The Timeless Art of Porno Music. Vice.com, 4.4.2014, <https://www.vice. com/en_au/article/69vp3r/the-timeless-art-of-porno-music> (Linkki tarkistettu 26.6.2019.)

O'Connor, Roisin (2019) The 40 greatest film soundtracks of all time, from Flashdance to Pulp Fiction. The Independent, 26.5.2019, <https://www.independent.co.uk/arts-entertainment/music/ features/best-film-sound tracks-classic-greatest-essential-songs-movies-list-a8836591.html> (Linkki tarkistettu 25.6.2019.)

Oscars (2019) 92 $2^{\text {nd }}$ Oscars Rules. Oscars.org, <https://www.oscars.org/sites/oscars/files/92aa_rules.pdf> (Linkki tarkistettu 26.6.2019.) 